\title{
Placental Transfer of Analogs of Glucose and Amino Acids in Experimental Intrauterine Growth Retardation
}

\author{
MENACHEM NITZAN, SHELDON ORLOFF, AND JOSEPH D. SCHULMAN ${ }^{35}$ \\ Section on Human Biochemical and Developmental Genetics, National Institute of Child Health and Human \\ Development, National Institutes of Health, Bethesda, Maryland, USA
}

\section{Summary}

We have employed the model in which one uterine artery is ligated to study maternofetal transport and tissue uptake of glucose and amino acids in the intrauterine growth-retarded rat. On the 18th day of gestation, the artery supplying one uterine horn was ligated. Two days later the rats received $\left[{ }^{3} \mathrm{H}\right] 2$-deoxyglucose and $\left.\right|^{14} \mathrm{C} \mid \alpha$-aminoisobutyric acid iv. One hour later the growthretarded and control fetuses were delivered by Cesarean section and appropriate blood samples were obtained. The growth-retarded fetuses had an average weight reduction of $27 \%$, significantly increased placental to fetal weight ratio and brain to body ratio, and a significantly reduced liver to body ratio. Total radioactivity derived from tritiated deoxyglucose in whole fetal tissues, placenta, liver, and brain were significantly decreased in the intrauterine growth-retarded (IUGR) fetuses; this was also true per gram of tissue except for liver. Liver to plasma, brain to plasma, and whole fetal tissue to plasma ${ }^{3} \mathrm{H}$ ratios were significantly increased in the IUGR group. The radioactivity derived from $\left|{ }^{14} \mathrm{C}\right| \alpha$-aminoisobutyric acid was significantly reduced in whole fetal tissues, placenta, liver, and brain in the IUGR fetuses whether expressed per whole organ or per gram of tissue. Significant differences in liver to plasma, brain to plasma, and whole tissue to plasma ${ }^{14} \mathrm{C}$ ratios were not observed.

\section{Speculation}

The large reduction in maternofetal transfer of deoxyglucose and $\alpha$-aminoisobutryric acid when uterine blood flow is reduced raises the possibility that one of the major causes of retarded growth in utero is a diminished supply of glucose and amino acids to the fetus. The fetal liver appears to be especially effective in increasing its extraction of 2-deoxyglucose from fetal plasma during this period of nutrient restriction. Since a major cause of fetal growth retardation in man is an impairment in maternal circulatory supply to the placenta, a similar mechanism of growth retardation may contribute to human IUGR. The possibility that nutritional supplementation may be of value in improving the growth conditions for the fetus when uterine blood flow is restricted would seem worthy of further investigation. More information is also required about the mechanisms responsible for the apparent improved extraction of glucose from plasma in IUGR.

In developed societies, a major cause of fetal malnutrition and growth retardation may be an impairment in maternal circulatory supply to the placenta (12). Glucose and amino acids are among the important nutrients supplied by the mother to the fetus (24). Since the fetus is entirely dependent upon the maternal circulation for nutrition, a significant reduction in uteroplacental blood flow might limit the supply of these critical substrates to the growing fetus, resulting in intrauterine malnutrition.
The available information on the qualitative and quantitative aspects of maternofetal transfer of these nutrients, as well as data concerning possible alterations in their tissue distribution during conditions of limited transfer are scanty.

In order to gain more insight into maternofetal transport and tissue uptake of glucose and amino acids in IUGR, we have employed the model devised by Wigglesworth (31), in which the artery to one uterine horn is ligated. Our goal in these initial studies was primarily to test the assumption that in this model uterine blood flow restriction limits the rate of glucose and amino acid transport to the placenta and fetus. To the best of our knowledge, this assumption has not been examined in any animal system where maternal flow restriction has been induced. In exploring placental transport and tissue uptake, further metabolism of the compounds in question should ideally be excluded. For this reason radioactive analogs of glucose and amino acids known to undergo little or no further intracellular alteration were used. The results of some of our initial studies are reported here.

\section{MATERIALS AND METHODS}

\section{ANIMALS AND SURGICAL PROCEDURE}

The experiment involved six pregnant Sprague-Dawley rats with accurately timed gestations (within $12 \mathrm{hr}$ ). They were caged individually and given free access to Purina laboratory pellets and tap water until the time of surgery. Experimental intrauterine growth retardation was induced by slight modification (18) of a previously described procedure (31). On the 18th day of gestation, a lower midline laparotomy was performed under ether anesthesia. The uterus was exposed and the uterine artery supplying one uterine horn was ligated with two silk ligatures. The artery of the opposite uterine horn was left untouched. Following surgical intervention the incision was immediately closed with silk sutures. Two days later, the pregnant rats received $25 \mathrm{mCi}\left[{ }^{3} \mathrm{H}\right] 2$-deoxyglucose $(10 \mathrm{Ci} / \mathrm{mM})$ and $1 \mu \mathrm{Ci}\left[{ }^{14} \mathrm{C}\right] \alpha$-aminoisobutyric acid (AIB) $(9$ $\mathrm{mCi} / \mathrm{mM}) / 100 \mathrm{~g}$ of body weight iv. These compounds were obtained as high purity radiochemicals from Amersham/Searle and were not repurified before use. Sixty minutes after the injections, the 15 living IUGR and 27 control fetuses were delivered by Cesarean section. Heparinized blood samples were obtained from the maternal abdominal aorta just prior to removal of the fetuses and fetal blood samples were taken from deep neck incisions immediately after delivery.

The placenta, liver, and brain of each fetus, as well as the remaining fetal tissues were freed from surrounding membranes, lightly blotted, and promptly frozen, weighed, and homogenized in distilled water. The homogenates were carefully diluted to $10 \%$ tissue $(w / w)$, centrifuged, and a $0.5-\mathrm{ml}$ aliquot of the supernatant fluid was counted in $15 \mathrm{ml}$ Aquasol. This method is virtually the same as that used by Young and Widdowson (33). Essentially, all 
of the counts derived from the labeled substrates after digestion of selected homogenates with NCS solubilizer (Amersham/Searle) were found in the supernatants. For statistical analysis, the results from the normal or stunted newborns from each litter were pooled; averaged, and used as a single observation. Whole fetal tissue data given in the tables are the sum of analyses of liver, brain, and remaining carcass weights or radioactivities, excluding the placenta. Radioactive products were not further analyzed.

\section{RESULTS}

\section{MORPHOMETRIC FINDINGS}

These findings are summarized in Table 1 and confirm the validity of the model. In particular, average liver weight was much smaller in the IUGR fetuses, while the reduction in brain weight amounted to only $12 \%$. The liver to body ratio was significantly smaller in the IUGR group, while brain to body ratio was significantly greater than in the controls, similar to results shown pre- viously by Wigglesworth (31). This nonuniform fetal growth retardation is characteristic of type I IUGR, associated with maternal vascular disturbances.

\section{PLACENTAL TRANSFER AND TISSUE UPTAKE OF ["H]2- DEOXYGLUCOSE (TABLES 2-4)}

The radioactivity of 2-deoxyglucose in fetal plasma as well as its mean fetal to maternal plasma ratio averaged $34 \%$ less in the IUGR group. Total radioactivity in whole fetal tissues, placenta, liver, and brain were also significantly decreased. When expressed per gram of tissue, the uptake of 2-deoxyglucose was significantly smaller in IUGR fetuses and placentas. Although brain uptake of 2-deoxyglucose/g was significantly smaller in the IUGR fetuses, liver uptake per gram showed an opposite trend, although the difference did not reach statistical significance. Liver to plasma ratio and brain to plasma ratios averaged 73 and $24 \%$, respectively, greater in the IUGR group and whole fetal tissue to plasma ratios were also significantly higher.

Table 1. Morphometric finding ${ }^{1}$

\begin{tabular}{lcccc}
\hline \multicolumn{1}{c}{ Weight $(\mathrm{g})$} & IUGR & Control & $\boldsymbol{P}$ & Mean from control (\%) \\
\hline Total fetus & $2.22 \pm 0.37$ & $3.03 \pm 0.43$ & $<0.001$ & -26.7 \\
Placenta & $0.476 \pm 0.028$ & $0.514 \pm 0.038$ & $>0.05$ & -7.4 \\
Liver & $0.125 \pm 0.023$ & $0.210 \pm 0.033$ & $<0.001$ & -40.2 \\
Brain & $0.125 \pm 0.010$ & $0.141 \pm 0.013$ & $<0.02$ & -11.5 \\
Ratios & & & & \\
Placenta/fetus & $0.237 \pm 0.034$ & $0.182 \pm 0.022$ & $<0.01$ & +30.2 \\
Liver/fetus & $0.056 \pm 0.003$ & $0.069 \pm 0.001$ & $<0.001$ & -18.8 \\
Brain/fetus & $0.060 \pm 0.005$ & $0.049 \pm 0.003$ & $<0.01$ & +22.5 \\
\hline
\end{tabular}

'Values are means \pm SE. Statistical analysis was performed by Student's $t$ test for paired samples.

Table 2. Tissue radioactivity (total $\mathrm{cpm}^{1}$ )

\begin{tabular}{|c|c|c|c|c|}
\hline & IUGR & Control & $P$ & $\begin{array}{c}\text { Mean from control } \\
(\%)\end{array}$ \\
\hline \multicolumn{5}{|c|}{$\left[{ }^{3} \mathrm{H}\right] 2$-deoxyglucose } \\
\hline Fetus & $480,839 \pm 93,698$ & $766,783 \pm 126,622$ & $<0.01$ & -41.1 \\
\hline Placenta & $112,887 \pm 7,337$ & $139,998 \pm 12,416$ & $<0.01$ & -19.4 \\
\hline Liver & $27,087 \pm 4,917$ & $37,833 \pm 3,981$ & $<0.01$ & -28.4 \\
\hline Brain & $26,972 \pm 5,187$ & $36,400 \pm 6,443$ & $<0.02$ & -25.9 \\
\hline \multicolumn{5}{|l|}{$\left[{ }^{14} \mathrm{C}\right] \mathrm{AIB}$} \\
\hline Fetus & $9,425 \pm 2,117$ & $22,722 \pm 4,776$ & $<0.01$ & -58.5 \\
\hline Placenta & $3,680 \pm 306$ & $5,992 \pm 621$ & $<0.01$ & -38.6 \\
\hline Liver & $517 \pm 85$ & $1,101 \pm 173$ & $<0.01$ & -53.0 \\
\hline Brain & $247 \pm 22$ & $454 \pm 57$ & $<0.01$ & -45.6 \\
\hline
\end{tabular}

' Values are means \pm SE. Statistical analysis was performed by Student's $t$ test for paired samples.

Table 3. Plasma and tissue radioactivity

\begin{tabular}{|c|c|c|c|c|}
\hline & IUGR & Control & $P$ & $\begin{array}{c}\text { Mean from control } \\
(\%)\end{array}$ \\
\hline \multicolumn{5}{|l|}{$\left[{ }^{3} \mathrm{H} 2\right.$-deoxyglucose } \\
\hline Maternal plasma & $104,397 \pm 9,861$ & $104,397 \pm 9861$ & & \\
\hline Fetal plasma & $48,157 \pm 7,514$ & $73,755 \pm 11,137$ & $<0.01$ & -34.7 \\
\hline Fetus & $206,333 \pm 20,125$ & $247,896 \pm 21,932$ & $<0.01$ & -16.8 \\
\hline Placenta & $238,487 \pm 12,553$ & $275,911 \pm 22,855$ & $<0.05$ & -13.6 \\
\hline Liver & $225,134 \pm 29,185$ & $191,833 \pm 22,013$ & $<0.05$ & +17.4 \\
\hline Brain & $214,500 \pm 40,216$ & $256,479 \pm 37,418$ & $<0.05$ & -16.4 \\
\hline \multicolumn{5}{|l|}{$\left[{ }^{14} \mathrm{C}\right] \mathrm{AIB}$} \\
\hline Maternal plasma & $6,357 \pm 715$ & $6,357 \pm 715$ & & \\
\hline Fetal plasma & $3,966 \pm 413$ & $6,180 \pm 557$ & $<0.001$ & -35.8 \\
\hline Fetus & $4,119 \pm 408$ & $7,388 \pm 1073$ & $<0.01$ & -44.3 \\
\hline Placenta & $7,821 \pm 630$ & $11,920 \pm 1400$ & $<0.02$ & -34.4 \\
\hline Liver & $4,225 \pm 248$ & $5,397 \pm 581$ & $>0.05$ & -21.7 \\
\hline Brain & $2,006 \pm 170$ & $3,190 \pm 259$ & $<0.01$ & -37.1 \\
\hline
\end{tabular}

\footnotetext{
${ }^{\prime}$ Results have been expressed as $\mathrm{cpm} / \mathrm{ml}$ or $\mathrm{cpm} / \mathrm{g}$. Values are means \pm SE. Statistical analysis was performed by Student's $t$ test for paired samples.
} 
Table 4. Ratios of radioactivity in plasma, fetus, placenta, and fetal liver and brain

\begin{tabular}{|c|c|c|c|c|}
\hline & IUGR & Control & $P$ & $\begin{array}{c}\text { Mean from control } \\
(\%)\end{array}$ \\
\hline \multicolumn{5}{|l|}{$\left[{ }^{3} \mathrm{H}\right] 2$-deoxyglucose } \\
\hline Plasma fetal/maternal & $0.453 \pm 0.039$ & $0.690 \pm 0.051$ & $<0.01$ & -34.2 \\
\hline Fetus/plasma & $5.095 \pm 1.041$ & $4.105 \pm 1.024$ & $<0.01$ & +24.1 \\
\hline Liver/plasma & $5.257 \pm 1.016$ & $3.042 \pm 0.811$ & $<0.001$ & +72.8 \\
\hline Brain/plasma & $4.643 \pm 0.681$ & $3.761 \pm 0.534$ & $<0.02$ & +23.5 \\
\hline \multicolumn{5}{|l|}{$\left[{ }^{14} \mathrm{C}\right] \mathrm{AIB}$} \\
\hline Plasma fetal/maternal & $0.634 \pm 0.045$ & $0.987 \pm 0.0414$ & $<0.001$ & -35.8 \\
\hline Fetus/plasma & $1.049 \pm 0.090$ & $1.234 \pm 0.193$ & $>0.05$ & -15.0 \\
\hline Liver/plasma & $1.167 \pm 0.170$ & $0.919 \pm 0.133$ & $>0.05$ & +27.0 \\
\hline Brain/plasma & $0.531 \pm 0.064$ & $0.545 \pm 0.060$ & $>0.05$ & -2.6 \\
\hline
\end{tabular}

' Ratios are derived from individual data used for calculating results given in Table 3. Values are means \pm SE. Statistical analysis was performed by Student's $t$ test for paired samples.

\section{PLACENTAL TRANSFER AND TISSUE UPTAKE OF AIB (TABLES 2-4)}

The radioactivity of AIB in fetal plasma and its mean fetal to maternal ratio were reduced an average of $36 \%$ in the IUGR group. Total radioactivity in whole fetal tissues, placenta, liver, and brain was significantly smaller in IUGR fetuses.

When expressed per gram of tissue, fetal, placental, liver, and brain radioactivity was also significantly smaller in IUGR fetuses. Liver to plasma ratio was greater in the IUGR group, although the difference did not reach statistical significance. No trend toward differences was noted in brain to plasma ratios or whole fetus to plasma ratios.

\section{DISCUSSION}

Fetal nutrition depends not only on an adequate source of nutrients, but also on their efficient delivery to the fetus. A reduction in uteroplacental blood flow, which was the cause of experimental IUGR in this study, may play an important role in human IUGR as well. In certain conditions, such as preeclampsia $(10)$, hypertension $(2,10)$, and supine hypotension (3), the usual circulatory adjustments required to ensure optimal maternal perfusion of the placenta site fail to occur.

Active transfer of glucose and amino acids across the placenta is well documented in several species $(6,8,11,14,17,23)$. To investigate whether a reduction in uteroplacental blood supply interferes with adequate transport of these nutrients, we have employed labeled analogs in this study. Although 2-deoxyglucose is a most suitable analog for use in studies of glucose transport ( 1 , 13, 28-30), we are unaware of its previous use in examination of maternofetal glucose transfer. It differs from glucose in the replacement of the hydroxyl group on the second carbon atom by a hydrogen atom, and they share a common transport system. 2Deoxyglucose is converted to 2-deoxyglucose-6-phosphate by hexokinase, but this product is not metabolized further by glycolysis or the hexose monophosphate shunt, nor it is known to be incorporated into glycogen. It appears to be a very poor substrate for rat liver glucose-6-phosphatase $(2,3,10,33)$. AIB was selected as an analog of the naturally occurring amino acids because it is not metabolized in mammalian tissues, but is transported by the same system which utilizes alanine, glycine, and a variety of other amino acids $(5,25)$.

Joyce and Young (15) and Krauer et al. (16) have shown by in situ perfusion of the guinea pig placenta that transfer rates of glucose and AIB are related to the maternal blood flow. Furthermore, a single spontaneous guinea pig runt fetus accumulated less than normal quantities of AIB that had been injected into the maternal circulation at the end of gestation (32). There is no published data of which we are aware documenting the status of fetal nutrient transfer in flow-restricted cases of IUGR in any species, except for umbilical artery ligation in the sheep (22). In the IUGR rat model employed in this study, as well as in a substantial proportion of human pregnancies associated with IUGR, fetal growth impairment is associated with restricted uter- oplacental blood supply. Our findings in the experimental model prove that there is a large reduction in the maternofetal transfer of 2-deoxyglucose and AIB when uterine blood flow is reduced. This result provides objective documentation of the impaired transfer previously only assumed in this widely used animal model of IUGR.

Neonatal hypoglycemia occurs predominantly in newborns whose birth weights are low for gestational age $(7,19)$. Toward the end of gestation large glycogen reserves are built up in the fetal liver in all mammalian species which have been examined (27). In contrast, low levels of hepatic glycogen have been found in IUGR human infants at necropsy $(9,26)$. In experimentally induced IUGR rat fetuses, a reduction of liver glycogen content was also observed $(30,31)$. The reduced transfer of glucose across the placenta demonstrated in this study may play an important role in the reduced blood glucose concentrations reported in IUGR rat fetuses immediately following delivery $(4,20,21)$, as well as in the diminished glycogen reserves associated with retarded fetal growth.

Interestingly, the IUGR fetal tissues demonstrated an increase in extraction of 2-deoxyglucose from plasma, which was observed in the whole fetus, liver, and brain. Liver appears to be especially effective in this regard, since uptake of 2-deoxyglucose per gram of tissue was not decreased and even showed a trend toward increase in IUGR livers. However, such possible adaptation was not effective in normalizing the uptake of 2-deoxyglucose in other tissues, including brain. There was also a trend toward enhanced liver extraction of AIB from fetal plasma in the IUGR group, but this trend was not significant. No such trend was noted in the whole fetus or brain. The mechanism and physiologic significance of these apparent changes in tissue accumulation of glucose and amino acid analogs in IUGR require further elucidation. Although some of these changes may be explained by a reduced level of the natural substrates in extracellular pools compared with the labeled compounds sharing common transport systems with them, the interorgan differences observed indicate that the full explanation of these alterations is more complex.

\section{CONCLUSION}

In initial studies in the rat using the experimental IUGR model associated with restricted uterine blood supply, we have tested the assumption that there is a reduction in maternofetal nutrient transfer to IUGR fetuses. By using a radioactive 2-deoxyglucose and AIB, reduced transfer was demonstrated to placenta, fetal plasma, whole fetus, liver, and brain. Thus, the retarded growth in utero in this model can reasonably be explained, at least in part, by diminished supply of amino acids and glucose to the fetus. The reduced transfer of glucose across the placenta may play an important role in the diminished glycogen reserves and neonatal hypoglycemia associated with retarded fetal growth. Fetal tissues, particularly the liver, adapt to the reduced glucose supply by enhanced extraction of glucose from the circulation. 


\section{REFERENCES AND NOTES}

1. Bachelard, H. S.: Specificity and kinetic properties of monosaccharide uptake into guinea pig cerebral cortex in vitro. J. Neurochem., 18: 213 (1971).

2. Browne, J. C., and Veall, N.: The maternal placental blood flow in normotensive and hypertensive women. J. Obstet. Gynaecol. Br. Commonw., 60: 141 (1953).

3. Caldeyro-Barcia, R.: Fetal malnutrition: the role of maternal blood flow. Hosp. Pract., 5: 33 (1970).

4. Chanez, C., Roux, J. M., and Tordet-Caridroit, C.: Glycemie, glycogene et glucose-6-phosphatase dans le foie, a la periode perinatale, chez le rat dysmature. C. R. Secances Soc. Biol., I63: 2272 (1969).

5. Christensen, H. L., Aspeta A. J., and Rice, E. G.: Metabolism in the rat of three amino acids lacking $\alpha$-hydrogen. J. Biol. Chem., 220: 287 (1956).

6. Christensen, H. N., and Streicher, J. A.: Association between rapid growth and elevated cell concentrations of amino acids. I. In fetal tissues. J. Biol. Chem., 175: 95 (1948).

7. Cornblath, M., Wybregt, S. H., Baens, G. S., and Klein, R. I.: Symptomatic neonatal hypoglycemia: Studies of carbohydrate metabolism in the newborn infant. Pediatrics, 33: 388 (1964).

8. Crumpler, H. R., Dent, C. E., and Lindan, O.: The amino-acid pattern in human foetal and maternal plasma at delivery. Biochem. J., 47: 233 (1950).

9. Dawkins, M. J. R.: Hypoglycemia in childhood. Proc. R. Soc. Med., 57: 1063 (1964).

10. Dixon, H. G., and Robertson, W. B.: Vascular changes in the placental bed. Pathol. Microbiol., 24: 622 (1961).

11. Ely, P. A.: The placental transfer of hexoses and polyols in the guinea-pig, as shown by umbilical perfusion of the placenta. J. Physiol., 184: 225 (1966).

12. Gruenwald, P.: Pathology of the deprived fetus and its supply line. In: Size at Birth, p. 3 Ciba Foundation Symposium 27 (new series). (Elsevier, Amsterdam. 1974).

13. Horton, R. W., Meldrum, B. S., and Bachelard, H. S.: Enzymic and cerebral metabolic effects of 2-deoxy-D-glucose. J. Neurochem., 2l, 507 (1973).

14. Huggett, A. St. G.: Carbohydrate metabolism in the placenta and foetus. Br. Med. Bull., 17: 122 (1961).

15. Joyce, J., and Young, M.: A comparison of the effect of a reduction in maternal blood flow on the placental transfer of glucose and amino nitrogen from mother to foetus. J. Physiol., 239: 5p (1974).

16. Krauer, F., Joyce, J., and Young, M.: The influence of high maternal plasma glucose levels, and maternal blood flow on the placental transfer of glucose in the guinea pig. Diabetologia, 9: 453 (1973)

17. Lumley, T., and Wood, C.: Influence of hypoxia on glucose transport across the human placenta. Nature (Lond). 216: 403 (1967).

18. Manniello, R. L., Adams, A. J., and Farrell, P. M.: The influence of antenatal corticosteroids on hypoglycemia in newborn rats with intrauterine growth

Copyright $(\odot 1979$ International Pediatric Research Foundation, Inc. $0031-3998 / 79 / 1302-0100 \$ 02.00 / 0$ retardation. Pediatr. Res., 11: 840 (1977).

19. Neligan, G. A., Robson, E., and Watson, J.: Hypoglycemia in the newborn. A sequel of intrauterine malnutrition. Lancet $I: 1282$ (1963).

20. Nitzan, $M$. and Groffman, $H$.: Metabolic changes in experimental intrauterine growth retardation: Blood glucose and liver glycogen in dysmature and premature newborn rats. Isr. J. Med. Sci., 6: 697 (1970).

21. Oh, W., D'Amodio, M. D., Yap, L. L.. Hohenauer, L., and Metcoff, J.: Glycogen synthesis in experimental intrauterine fetal growth retardation. Pediatr. Res., 2: 415 (1968).

22. Oh, W., Omori, K., Hobel, C., et al.: Umbilical blood flow and glucose uptake in lamb fetus following single umbilical artery ligation. Biol. Neonate, 26: 291 (1975)

23. Page, E. W., Glendening, M. B., Margolis, A., and Harper, H. A. Transfer of D and L-Histidine across the human placenta. Am. J. Obstet. Gynecol., 73: 589 (1957).

24. Page, E. W., Villee, C. A., and Villee, D. B. Human Reproduction, p. 187 (W. B. Saunders Company, Philadelphia 1976).

25. Schwartz, A.: Hormonal regulation of amino acid accumulation of human fetal liver explants. Effects of dibutyryl cyclic AMP, glucagon and insulin. Bioch. Biophys. Acta, 362: 276 (1974).

26. Shelley, H. J.: Glycogen reserves and their changes at birth and in anoxia. Br. Med. Bull., 17: 137 (1961).

27. Shelley, H. J.: Carbohydrate reserves in the newborn infant. Br. Med. J., I: 273 (1964).

28. Sols, A., and Crane, R. K. Substrate specificity of brain hexokinase. J. Biol. Chem., 210: 581 (1954).

29. Tower, D. B.: The effects of 2-deoxy-D-glucose in metabolism of slices of cerebral cortex incubated in vitro. J. Neurochem., 3: 185 (1958)

30. Wick, A. N., Drury, D. R., Nakada, H. I., and Wolfe, J. B.: Localization of the primary metabolic block produced by 2-deoxyglucose. J. Biol. Chem., 224: 963 (1957).

31. Wigglesworth, J. C.: Experimental growth retardation in the foetal rat. J. Pathol. Bacteriol. 88: 1 (1964).

32. Young. M.: Three topics in placental transmission. In: A. Klopper and E. Diczfalusy: Fetus and Placenta, p. 139 (Blackwell Scientific Publications, Oxford, 1969)

33. Young, M., and Widdowson, E. M.: The influence of diets deficient in energy, or in protein, on conceptus weight, and the placental transfer of a non-metabolizable amino acid in guinea pig. Biol. Neonate, 27: 184 (1975).

34. Dr. M. Nitzan is: Department of Pediatrics, Beilinson Medical Center, PetahTikva and Sackler School of Medicine. Tel-Aviv University, Tel-Aviv, Israel.

35. Joseph D. Schulman, M.D., National Institute of Health, Building 10, Room 13N258, Bethesda, MD. 20014

36. Recieved for publication November 22, 1978.

37. Accepted for publication March 29, 1978

Printed in U.S.A. 